\title{
Monocyte-derived tissue transglutaminase in multiple sclerosis patients: reflecting an anti-inflammatory status and function of the cells?
}

Claudia Sestito 1,6 John J. P. Brevé ${ }^{1}$, Marja C. J. A. van Eggermond², Joep Killestein ${ }^{3}$, Charlotte E. Teunissen ${ }^{4}$, Joram van Rossum³ ${ }^{3}$ Micha M. M. Wilhelmus', Benjamin Drukarch', Peter J. van den Elsen ${ }^{2,5}$

and Anne-Marie van Dam ${ }^{1 *}$

\begin{abstract}
Background: Leukocyte infiltration into the central nervous system is an important feature of multiple sclerosis (MS) pathology. Among the infiltrating cells, monocytes comprise the largest population and are considered to play a dual role in the course of the disease. The enzyme tissue transglutaminase (TG2), produced by monocytes, plays a central role in monocyte adhesion/migration in animal models of MS. In the present study, we questioned whether TG2 expression is altered in monocytes from MS patients compared to healthy control $(\mathrm{HC})$ subjects. Moreover, we determined the inflammatory status of these TG2-expressing monocytes, what inflammatory factor regulates TG2 expression, and whether TG2 can functionally contribute to their adhesion/migration processes.

Methods: Primary human monocytes from MS patients and HC subjects were collected, RNA isolated and subjected to qPCR analysis. Human THP-1 monocytes were lentivirally transduced with TG2 siRNA or control and treated with various cytokines. Subsequently, mRNA levels of inflammatory factors, adhesion properties, and activity of RhoA were analyzed in interleukin (IL)-4-treated monocytes.

Results: TG2 mRNA levels are significantly increased in monocytes derived from MS patients compared to HC subjects. In addition, correlation analyses indicated that TG2-expressing cells display a more anti-inflammatory, migratory profile in MS patients. Using THP-1 monocytes, we observed that IL-4 is a major trigger of TG2 expression in these cells. Furthermore, knockdown of TG2 expression leads to a pro-inflammatory profile and reduced adhesion/migration properties of IL-4-treated monocytes.
\end{abstract}

Conclusions: TG2-expressing monocytes in MS patients have a more anti-inflammatory profile. Furthermore, TG2 mediates IL-4-induced anti-inflammatory status in THP-1 monocytes, adhesion, and cytoskeletal rearrangement in vitro. We thus propose that IL-4 upregulates TG2 expression in monocytes of MS patients, driving them into an anti-inflammatory status.

Keywords: Multiple sclerosis, Tissue transglutaminase, Inflammation, Human monocytes, Cytokine, Adhesion/migration

\footnotetext{
*Correspondence: amw.vandam@vumc.nl

${ }^{1}$ Department of Anatomy and Neurosciences, Amsterdam Neuroscience, $\mathrm{VU}$

University Medical Center, Postbus 7057, 1007 MB Amsterdam, the

Netherlands

Full list of author information is available at the end of the article
}

(c) The Author(s). 2017 Open Access This article is distributed under the terms of the Creative Commons Attribution 4.0 International License (http://creativecommons.org/licenses/by/4.0/), which permits unrestricted use, distribution, and reproduction in any medium, provided you give appropriate credit to the original author(s) and the source, provide a link to the Creative Commons license, and indicate if changes were made. The Creative Commons Public Domain Dedication waiver (http://creativecommons.org/publicdomain/zero/1.0/) applies to the data made available in this article, unless otherwise stated. 


\section{Background}

Multiple sclerosis (MS) is a chronic neurological disorder affecting mostly young adults that leads to, e.g., sensory, motor, and cognitive deficits [1]. Pathologically, it is characterized by inflammation, demyelination, and axonal loss in the central nervous system (CNS) [2]. Although the pathophysiology is not well understood, MS results in leukocyte infiltration into the CNS parenchyma which requires passage of the blood-brain barrier (BBB) [3]. This process is initiated by the secretion of cytokines and chemokines which induce leukocyte activation by stimulating conformational changes in the integrins, key regulators of the adhesion/migration cascade. These changes, together with cytoskeleton rearrangement and the secretion of matrix metalloproteinase (MMP) capable of cleaving components of the extracellular matrix (ECM), allow the arrest and finally the migration of the cells into the CNS [4, 5]. Monocytes and monocyte-derived macrophages constitute the major cell type in the perivascular infiltrates characteristic of several neuroinflammatory diseases including MS [6-9] and are considered to play a pivotal role in MS pathology. Indeed, depletion of monocytes and macrophages or inhibition of monocyte recruitment to the CNS leads to a reduction of clinical symptoms and pathology in animals suffering from experimental autoimmune encephalomyelitis (EAE), an animal model of MS [7, 10, 11]. Once migrated into the $\mathrm{CNS}$, the recruited monocytes/macrophages, together with the locally activated microglia, release proteases, proinflammatory cytokines, and reactive oxygen species, contributing to myelin damage and, ultimately, axonal damage $[12,13]$. Although monocytes/macrophages are thought to primarily have detrimental effects on MS pathogenesis and development, other studies point toward a dual role for these cells since it has been proven that they can also contribute to the clearance of tissue debris and promote tissue repair by secreting growth factors and anti-inflammatory cytokines, such as nerve growth factor (NGF) and interleukin (IL)-10 [14-16]. Furthermore, administration of anti-inflammatory-tuned monocytes to animals suffering from severe EAE ameliorates their clinical disease status [17-19].

Tissue transglutaminase, or transglutaminase 2 (TG2), is a calcium-dependent protein-crosslinking enzyme whose expression and activity can be increased by inflammatory mediators in various cell types, including monocytes [20-23]. A recent study from our group demonstrated TG2 immunoreactivity in human active MS lesions in infiltrating cells of which some express MHC-II. In addition, we observed in an animal experimental MS model that TG2 is present in infiltrating monocytes and contributes to pathology by promoting monocyte migration into the CNS [24]. Of interest is that TG2 has also been shown to be involved in the adhesion of monocytes onto ECM proteins in vitro (i.e., fibronectin, $\mathrm{FN}$ ) as it serves as a $\beta$-integrin-associated co-receptor promoting binding to fibronectin [25].

Thus, we hypothesize that in monocytes of MS patients, TG2 expression is altered due to the inflammatory environment. Consequently, TG2 expressed by monocytes could contribute to adhesion and migration processes that are essential for cells entering the CNS, resulting in MS pathology. In the present study, we studied TG2 expression in monocytes from MS patients and healthy control $(\mathrm{HC})$ subjects and we determined the inflammatory status of the TG2-expressing monocytes. In addition, using the human THP-1 monocyte cell line, we studied the regulation of TG2 expression by inflammatory mediators and its possible functional implication in monocyte adhesion/migration processes.

\section{Methods}

\section{Isolation of primary human monocytes}

Peripheral blood mononuclear cells (PBMCs) were obtained from $15 \mathrm{MS}$ patients (13 relapsing-remitting and 3 primary progressive, RR-MS, and PP-MS respectively) diagnosed according to the Poser or McDonald criteria [26] and $10 \mathrm{HC}$ subjects (Table 1). MS patients were recruited from the VU University Medical Center (VUmc) outpatient clinic while participating in different prospective cohort studies. Age and sex-matched control subjects were recruited from the Leiden University Medical Center (LUMC). All participants gave informed consent, and the study was approved by the Medical Research Ethics Committees of the VUmc and LUMC, respectively. At time of blood collection, the activity status of the disease was not measured. Peripheral blood was drawn by venipuncture and collected into sodium citrate tubes (Greiner, Kremsmünster, Austria). One part of blood was diluted with one part of buffer consisting of phosphate-buffered saline (PBS) + 10\% v/v GPO (Sanquin, Amsterdam, The Netherlands) $+10 \% v / v$ sodium citrate. PBMCs were isolated by density centrifugation using Ficoll Isopaque PLUS (GE Healthcare Biosciences, Uppsala, Sweden). Monocytes were subsequently isolated from the PBMCs by anti-CD14 magnetic beads according to the manufacturer's instruction (MACS; Milteny Biotech, Bergisch Gladbach, Germany).

\section{Cell culture and treatment}

THP-1 cells (human monocytic cell line) were maintained in complete RPMI 1640 medium (Gibco, Waltham, Massachusetts, USA) containing 10\% heat-inactivated fetal calf serum (PAA), penicillin (50 units/ml, Gibco), streptomycin $(50 \mu \mathrm{g} / \mathrm{ml}$, Gibco), and L-glutamine (2 mM, Gibco) at $37{ }^{\circ} \mathrm{C}$ in humidified air containing $5 \% \mathrm{CO}_{2}$.

Scramble control (SCR) and TG2-knockdown (TG2-KD) THP-1 cell lines were generated by double, subsequent 
Table 1 Patient information

\begin{tabular}{|c|c|c|c|c|c|}
\hline Subjects & Number & Female/male & Age (years) $\pm S D$ & Type MS & DMT \\
\hline \multirow[t]{11}{*}{$\overline{\mathrm{HC}}$} & Total 10 & $4 / 6$ & $40 \pm 12$ & & \\
\hline & 1 & Female & 25 & - & - \\
\hline & 2 & Female & 49 & - & - \\
\hline & 3 & Female & 25 & - & - \\
\hline & 4 & Female & 46 & - & - \\
\hline & 5 & Male & 50 & - & - \\
\hline & 6 & Male & 42 & - & - \\
\hline & 7 & Male & 30 & - & - \\
\hline & 8 & Male & 39 & - & - \\
\hline & 9 & Male & 33 & - & - \\
\hline & 10 & Male & 60 & - & - \\
\hline \multirow[t]{16}{*}{ MS } & Total 15 & $8 / 7$ & $45 \pm 16$ & & \\
\hline & 11 & Female & 73 & PP-MS & Untreated \\
\hline & 12 & Male & 51 & PP-MS & Untreated \\
\hline & 13 & Male & 56 & PP-MS & Untreated \\
\hline & 14 & Female & 25 & RR-MS & Interferon beta-1a \\
\hline & 15 & Female & 71 & RR-MS & Untreated \\
\hline & 16 & Female & 24 & RR-MS & Glatiramer acetate \\
\hline & 17 & Female & 49 & RR-MS & Glatiramer acetate \\
\hline & 18 & Male & 30 & RR-MS & Interferon beta-1a \\
\hline & 19 & Male & 48 & RR-MS & Natalizumab \\
\hline & 20 & Female & 30 & RR-MS & Untreated \\
\hline & 21 & Female & 32 & RR-MS & Untreated \\
\hline & 22 & Female & 46 & RR-MS & Untreated \\
\hline & 23 & Male & 45 & RR-MS & Untreated \\
\hline & 24 & Male & 58 & RR-MS & Untreated \\
\hline & 25 & Male & 32 & RR-MS & Untreated \\
\hline
\end{tabular}

$H C$ healthy controls, MS multiple sclerosis, PP-MS primary progressive MS, RR-MS relapsing-remitting MS, SD standard deviation, DMT disease-modifying therapies

lentiviral transduction (MOI 1) with either a scramble or hTG2 specific short hairpin RNA (shRNA) (scramble: sc108080, hTG2: sc-37514-V, Santa Cruz, Dallas, Texas, USA) for $24 \mathrm{~h}$ for each infection.

To create stable knockdown cell lines, cells were selected with $2 \mathrm{mg} / \mathrm{ml}$ puromycin (Sigma-Aldrich, Saint Louis, Missouri, USA). Subsequently, the cells were characterized by western blot analysis and semi-quantitative real-time PCR (qPCR) (see below) and used for functional assays. Stable cell lines were maintained in complete RPMI in presence of $2 \mathrm{mg} / \mathrm{ml}$ puromycin.

THP-1 cells were either untreated or treated with $50 \mathrm{ng} / \mathrm{ml}$ of the human recombinant IL-4, IL-10, IL-1 $\beta$, or tumor necrosis factor (TNF)- $\alpha$ (BioLegend, San Diego, USA) for $24 \mathrm{~h}$ in culture medium. The dose of cytokine used was based on previous studies from our group [24, 27]. The incubation period was chosen based on the time-dependent TG2 expression in THP-1 cells showing that a 24-h treatment with cytokines resulted in the most increased TG2 expression (data not shown).

\section{RNA isolation and cDNA synthesis from primary human monocytes}

Primary human monocytes were centrifuged for $5 \mathrm{~min}$ at $500 \times g$. Cells were lysed in RNAbee (Tel-Test, Friendswood, USA) according to the manufacturer's instructions. Lysates were stored at $-80{ }^{\circ} \mathrm{C}$ until further processing. Total RNA was extracted according to the manufacturer's instructions. The RNA concentration was determined by measuring the absorbance at $260 \mathrm{~nm}$ (NanoDrop ND-100 spectophotometer; Thermo Fisher scientific, Waltham, USA) and when approved, samples were included for cDNA synthesis. From $1 \mu \mathrm{g}$ total RNA, cDNA was synthesized using Superscript III (Invitrogen, California, USA) with $250 \mathrm{ng}$ random hexamers (Promega, Wisconsin, USA) and according to the manufacturer's instructions. 
RNA isolation and CDNA synthesis from THP-1 cells THP-1 cells were homogenized in Trizol reagent (Invitrogen) and total RNA was isolated as described by the manufacturer. RNA concentration was determined by measuring the absorbance at $260 \mathrm{~nm}$ (NanoDrop ND1000 spectrophotometer) and when approved, samples were included for cDNA synthesis. Then, $1 \mu \mathrm{g}$ of total RNA was reverse-transcribed into cDNA using the HighCapacity cDNA Reverse Transcription kit (Life Technologies, California, USA), using $0.5 \mu$ g oligo-dT primers and according to the manufacturer's instructions.

\section{Semi-quantitative real-time PCR (qPCR)}

For qPCR, the Power SYBR Green Master Mix (Life Technologies) was used. Primers were purchased from Eurogentec (Liège, Belgium) and qPCR was performed in MicroAmp Optical 96-well Reaction Plates (Applied Biosystems, California, USA) on a StepOnePlus RealTime PCR system (Applied Biosystems). The reaction mixture $(20 \mu \mathrm{l})$ was composed of $1 \times$ Power SYBR Green buffer (Applied Biosystems), 3.75 pmol of each primer (Table 2), and 100 ng cDNA. The thermal cycling conditions were an initial $10 \mathrm{~min}$ at $95^{\circ} \mathrm{C}$ followed by $40 \mathrm{cy}$ cles of $15 \mathrm{~s}$ at $95{ }^{\circ} \mathrm{C}$ and $1 \mathrm{~min}$ at $60^{\circ} \mathrm{C}$. The specificity of the reaction was checked by melt curve analysis of the individual qPCR reaction. The relative expression level of the target genes was determined by the LinRegPCR software (http://www.hfrc.nl, downloads, applications, lin reg PCR, version 2017 ) using the following calculation $N 0=\mathrm{Nq} / E \mathrm{Cq} \quad(N 0=$ target quantity, $\mathrm{Nq}=$ fluorescence threshold value, $E=$ mean PCR efficiency per amplicon, $\mathrm{Cq}=$ threshold cycle) [28], after which the value was normalized relative to the geometric mean of the mRNA levels of glyceraldehyde-3-phosphate-dehydrogenase (GAPDH) and polymerase (RNA) II polypeptide F (POLR2F). We chose GAPDH and POLR2F as reference genes based on the results of the GeNorm software analysis (version 3.5) in which the stability of six different human housekeeping genes (GAPDH, MRIP, POLR2F, HPRT1, PGK1, SDHA) was assessed in our primary human monocytes. Regarding the THP-1 cells, the value was normalized relative to the mRNA levels of GAPDH as previously described [29].

\section{Western blotting (WB)}

To determine TG2 protein expression, cells were homogenized in ice-cold RIPA buffer containing $150 \mathrm{mM}$ $\mathrm{NaCl}, 20 \mathrm{mM}$ Tris- $\mathrm{HCl}$ (pH 7.4), 1\% NP-40, 1\% sodium deoxycholate, $1 \mathrm{mM}$ EDTA, $0.1 \%$ sodium dodecyl sulfate (SDS), $15 \mu \mathrm{M}$ Pepstatin A, $100 \mu \mathrm{M}$ phenylmethylsulfonyl fluoride (PMSF), $0.3 \mu \mathrm{M}$ aprotinin, and $15 \mu \mathrm{M}$ leupeptin. Cell lysates were cleared by centrifugation $\left(14.000 \mathrm{rpm}\right.$ for $10 \mathrm{~min}$ at $\left.4{ }^{\circ} \mathrm{C}\right)$. Protein concentration of the supernatant was determined by the bicinchoninic acid (BCA) method according to the instructions of the manufacturer (Pierce Biotechnology, Waltham, Massachusetts, USA).

Fifty micrograms of protein were denaturated by adding Laemmli buffer $(0.012 \%$ bromophenol blue, $5 \%$ glycerol, 1.6\% SDS, $125 \mathrm{mM}$ Tris $\mathrm{HCl} \mathrm{pH} \mathrm{6.8)} \mathrm{and} 50 \mathrm{mM}$ dithiothreitol (DTT). After boiling, the mixture was loaded on a $10 \%$ SDS-polyacrylamide gel and transferred onto a nitrocellulose membrane (Li-cor Biosciences, Lincoln, Nebraska, USA). Membranes were incubated overnight with the following primary antibodies: mouse anti- $\beta$-actin (1:10,000; Abcam, Cambridge, UK) and mouse anti-TG2 (Ab3, 1:2000; Thermo Scientific, Waltham, Massachusetts, USA) diluted in Li-cor buffer. For subsequent antigen detection, the membranes were incubated for $1 \mathrm{~h}$ at room temperature (RT) with corresponding IgG's labeled with IRDye $800 \mathrm{CW}$ or IRDye 680LT (1:10,000; Li-cor buffer) and subsequently scanned to detect fluorescence emission at 800 or $680 \mathrm{~nm}$, respectively, using an Odyssey infrared imaging system (Li-Cor

Table 2 Primer sequences

\begin{tabular}{|c|c|c|}
\hline Gene & Forward & Reverse \\
\hline TG2 & 5'AGAGGAGCGGCAGGAGTATG 3' & 5'AGGATCCCATCTTCAAACTGC $3^{\prime}$ \\
\hline GAPDH & 5'TCAAGGGCATCCTGGGCTAC 3' & 5'CGTCAAAGGTGGAGGAGTGG 3' \\
\hline POLR2F & 5'GAACTCAAGGCCCGAAAG 3' & 5'TGATGATGAGCTCGTCCAC 3' \\
\hline $\mathrm{IL}-1 \beta$ & 5'TACAGCTGGAGAGTGTAGATC 3' & 5'CAAATTCCAGCTTGTTATTG 3' \\
\hline TNF-a & 5'CCCAGGCAGTCAGATCATCTTC 3' & 5'CTCTCAGCTCCACGCCATTG 3' \\
\hline IL-1ra & 5'TCATCCGCTCAGACAGTGGC 3' & 5'AGCTTCCATCGCTGTGCAGA 3' \\
\hline TGF- $\beta 1$ & 5'CTTTCCTGCTTCTCATGGCC 3' & 5'CCGTGGAGCTGAAGCAATAG 3' \\
\hline$\beta 1$ integrin & 5'TGTGGAGGAAATGGTGTTGC 3' & 5'TCTGTCCGTTGCTGGCTTCA 3' \\
\hline$\beta 3$ integrin & 5'CAATGCCACCTGCCTCAACA 3' & 5'GAGTCTTCATAGTACTGGAATC 3' \\
\hline MMP-2 & 5'AAGGCCAAGTGGTCCGTGTG 3' & 5'GTGCAGCTGTTGTACTCCTTGC 3' \\
\hline
\end{tabular}


Biosciences). The signal intensity was measured using the Odyssey Sa Infrared scanning software (version 1.1, LiCor Biosciences).

\begin{abstract}
Adhesion assay
SCR or TG2-KD THP-1 monocytes were treated with $50 \mathrm{ng} / \mathrm{ml} \mathrm{IL-4}$. After $24 \mathrm{~h}$ treatment, cells were centrifuged and resuspended in adhesion medium (RPMI 1640 medium $+0.5 \%$ bovine serum albumin +25 mM HEPES). $5 \times 10^{4}$ of the treated cells were then added to a 96-well plate coated with $2 \mu \mathrm{g} / \mathrm{cm}^{2}$ bovine FN (Sigma-Aldrich). Cells were allowed to adhere to the FN layer at $37^{\circ}$ on an orbital shaker (Vibramax 100, Heidolph, Germany) at $300 \mathrm{rpm}$. After $1 \mathrm{~h}$, the non-adherent cells were removed and the adherent cells were labeled with $0.5 \mu \mathrm{M}$ calcein (Invitrogen) in the adhesion medium for $10 \mathrm{~min}$ at $37^{\circ}$. Then, excess of calcein was removed and cells were washed four times with PBS and lysed in $0.1 \mathrm{M} \mathrm{NaOH}$. The fluorescence (emission $485 \mathrm{~nm}$; extinction $520 \mathrm{~nm}$ ) was then measured using a spectrophotometer (Fluostar Galaxy Microplate Reader, BMG Lab Technologies, Germany) and using FluoStar Software (BMG Lab Technologies).
\end{abstract}

\section{RhoA GTPase activity assay}

To determine the effect of TG2 on cytoskeletal reorganization, we measured RhoA GTPase activity. $2 \times$ $10^{6} \mathrm{SCR}$ or TG2-KD THP-1 monocytes were treated with $50 \mathrm{ng} / \mathrm{ml} \mathrm{IL-4}$ for $24 \mathrm{~h}$. Thereafter, cells were lysed with lysis buffer $(50 \mathrm{mM}$ Tris, $\mathrm{pH} 7.6,150 \mathrm{mM} \mathrm{NaCl}$, 1\% Triton X-100, $20 \mathrm{mM} \mathrm{MgCl} 2,5 \mu \mathrm{g} / \mathrm{ml}$ Pepstatin A, $100 \mu \mathrm{M}$ PMSF, $5 \mu \mathrm{g} / \mathrm{ml}$ aprotinin, and $5 \mu \mathrm{g} / \mathrm{ml}$ leupeptin). Of the cleared lysates, $30 \mu \mathrm{g}$ was stored to determine the total amount of RhoA (total cell lysate). Remaining protein lysates were incubated with $60 \mu \mathrm{g}$ bacterially produced GST-RBD (Rho Binding Domain of Rhotekin) bound to glutathione-agarose beads (Cytoskeleton, USA) for $30 \mathrm{~min}$ at $4^{\circ}$. Beads were washed four times with lysis buffer containing $50 \mathrm{mM}$ Tris, $\mathrm{pH}$ 7.6, $150 \mathrm{mM} \mathrm{NaCl}, 1 \%$ Triton X-100, $10 \mathrm{mM} \mathrm{MgCl} 2$. Bound proteins were eluted in $30 \mu \mathrm{l}$ SDS Laemmli buffer and analyzed in parallel with the total cell lysate on a $12.5 \%$ SDS PAGE. The active form of RhoA and total RhoA were detected with a mouse monoclonal antibody (1:250, Santa Cruz Biotechnology) and were visualized as described under western blotting.

\section{Statistical analysis}

In the $\mathrm{HC}$ or MS patient-derived monocytes, the sample size varied between gene expression measurements due to availability of mRNA or cDNA or based on unreliable qPCR outcome (e.g., extreme values). Normal distribution of the data was tested using the Shapiro-Wilk procedure. When data from MS patients and $\mathrm{HC}$ were not normally distributed, either the logarithmic (for IL-1 $\beta$ and TNF- $\alpha$ ) or the cubic root transformed parameter (for $\beta 3$ Integrin) was used in order to normalize the variables. Subsequently, normally distributed data were analyzed by independent Student $t$ test. Correlation analysis was assessed using Pearson correlation analysis. The data obtained with the THP-1 cells all met the criteria of normal distribution. Subsequently, one-way analysis of variance (ANOVA) followed by Bonferroni post hoc test was performed for multiple comparisons while for two group analysis, an independent Student $t$ test was performed. Results were considered to be statistically significant if $p<0.05$. All statistical analyses were performed using SPSS software, version 20.0 (IBM Corp, NY, USA).

\section{Results}

TG2 mRNA levels were increased in MS patient-derived monocytes compared to $\mathrm{HC}$ subject-derived monocytes At first, we established that there was no significant difference in TG2 expression between untreated and drugtreated MS patients (see Additional file 1). Therefore, considering the relative low number of MS patients, all MS patient samples were further assessed as one group. When comparing TG2 mRNA levels between HC subjects and MS patients, there was a significant increase in TG2 expression in MS patient-derived monocytes compared to HC subject-derived monocytes $(p<0.001)$ (Fig. 1$)$.

\section{MS patient-derived monocytes showed a decrease in IL- $1 \beta$ mRNA and an increase in $\beta 3$ integrin mRNA levels compared to $\mathrm{HC}$ subject-derived monocytes}

Subsequently, we aimed to study the inflammatory phenotype of MS patient/HC subject-derived monocytes. We measured the expression of several pro- and antiinflammatory mediators. Interestingly, MS patientderived monocytes displayed a significant decrease in pro-inflammatory IL-1 $\beta$ expression compared to $\mathrm{HC}$ subject-derived monocytes $(p=0.003)$ (Fig. 2a), whereas pro-inflammatory TNF- $\alpha$ and anti-inflammatory IL-1 receptor antagonist (IL-1ra) and transforming growth factor (TGF)- $\beta 1$ mRNA levels were not significantly different (Fig. $2 b-d$ ). In addition, we examined whether the expression of two relevant members of the $\beta$ integrin family, $\beta 1$ and $\beta 3$, were also affected in monocytes derived from MS patients versus $\mathrm{HC}$ subjects. While $\beta 1$ integrin mRNA levels were not significantly different between the two groups (Fig. 3a), we observed a significant increase in $\beta 3$ integrin mRNA levels in MS patient-derived monocytes compared to HC subject-derived monocytes $(p=0.01)$ (Fig. 3b).

TG2 mRNA levels correlated with those of inflammatory mediators in MS patient-derived monocytes

Next, to determine the phenotype of TG2-expressing monocytes derived from MS patients and $\mathrm{HC}$ subjects, 


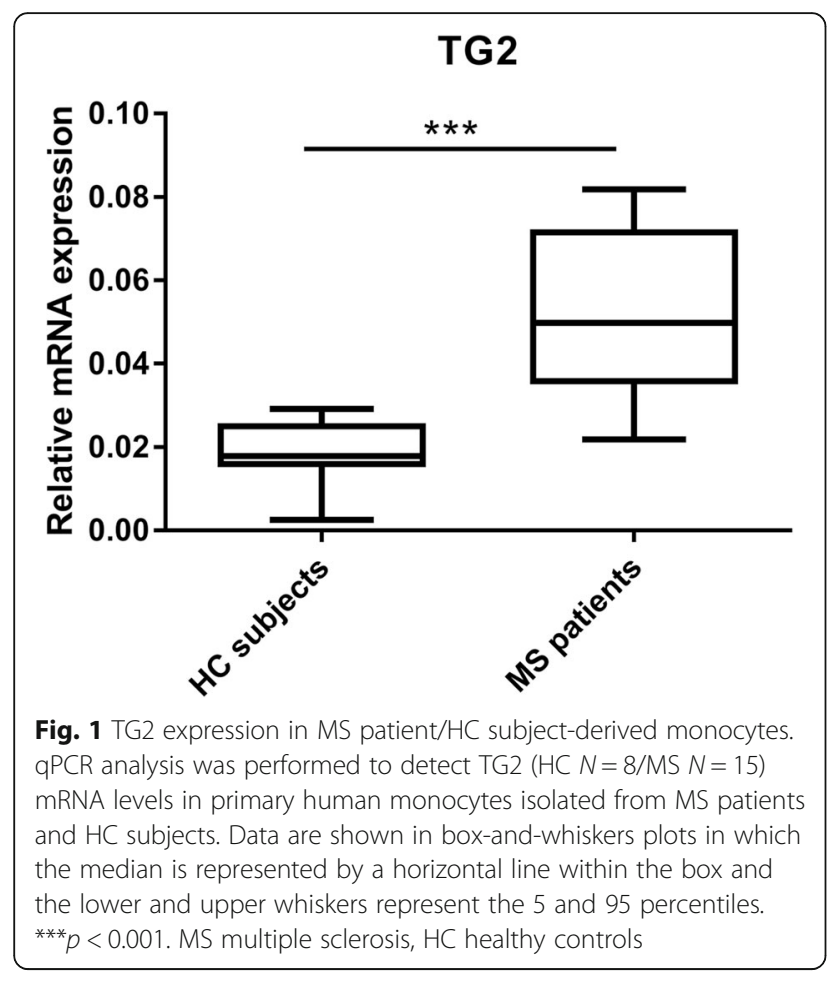

we correlated TG2 mRNA levels with mRNA levels of pro- and anti-inflammatory mediators. In MS patientderived monocytes (Fig. 4 black line), no significant correlation was observed between TG2 mRNA levels and either IL-1 $\beta$ mRNA levels $(r=0.376, p=0.168)$ or TNF $\alpha$ mRNA levels $(r=0.391, p=0.186)$ (Fig. 4a, b). However, TG2 mRNA levels correlated positively with the antiinflammatory mediators IL-1ra $(r=0.605, p=0.02)$ and TGF- $\beta 1(r=0.532, p=0.05)$ (Fig. 4c, d). None of these correlations was observed in $\mathrm{HC}$ subject-derived monocytes (Fig. 4a-d, gray line).

TG2 expression was upregulated in IL-4-treated monocytes and sustained an anti-inflammatory phenotype

To determine which inflammatory stimulus modulates TG2 expression in monocytes, as might occur during MS, THP-1 monocytes were either untreated or treated with two pro-inflammatory stimuli, i.e., IL-1 $\beta$ or TNF- $\alpha$ or with two anti-inflammatory stimuli, i.e., IL-4 or IL-10. The qPCR analysis revealed that TG2 mRNA levels were highly upregulated by IL-4 treatment (Fig. 5a). WB analysis confirmed the upregulation of TG2 protein in IL-4treated monocytes (Fig. 5b). Subsequently, we studied the relevance of TG2 in determining the phenotype of IL-4-treated monocytes, by using TG2-KD or SCR THP1 cells. First, we showed that in TG2-KD cells, TG2 mRNA (Fig. 6a) and protein levels (Fig. 6b) were significantly decreased after IL-4 treatment compared to IL-4- treated SCR cells. In addition, IL-4-treated TG2-KD cells expressed significantly more of the pro-inflammatory cytokines IL-1 $\beta$ and TNF $\alpha$ (Fig. 6c, d, respectively). Moreover, we observed a significant reduction in the mRNA level of the anti-inflammatory cytokine IL-1ra (Fig. 6e) in IL-4-treated TG2-KD monocytes.

\section{Effect of TG2-KD on adhesion and on cytoskeleton re- arrangement in IL-4-treated THP-1 cells}

To identify relevant functional aspects of TG2 in IL-4treated THP-1 monocytes, we studied adhesion properties. We observed that knockdown of TG2 expression resulted in less cell adhesion onto FN in response to IL4 (Fig. 7a). As $\beta$ integrins can act in concert with TG2 to promote cell adhesion, it was of interest to observe that IL-4-treated TG2-KD cells expressed significantly less $\beta 1$ integrin (Fig. 7b). In addition, we observed a reduction of almost $50 \%$ of active RhoA GTPase, indicative of reduced cytoskeletal rearrangement, in IL-4-treated TG2KD monocytes compared to SCR monocytes (Fig. 7c). Furthermore, IL-4-treated TG2-KD monocytes expressed significantly less MMP-2 (Fig. 7d), a protein known to be involved in the cleavage of ECM proteins and therefore permissive for cell migration [30, 31].

\section{Discussion}

Alteration in TG2 expression and/or cross-linking activity has been extensively implicated in the pathogenesis of various human diseases, including neurodegenerative disorders [32], coeliac disease [33], and cancer [34]. Thus, based on our previous observations in rat and mouse models for MS, we here questioned whether monocyte-derived TG2 expression was altered in MS patients. Although a limited number of patients was included in the present study, we are the first to show that TG2 mRNA levels are significantly enhanced in monocytes derived from MS patients compared to $\mathrm{HC}$ subjects. The presence of low levels of TG2 in human monocytes is known for many years. Moreover, inflammatory factors have been shown to enhance TG2 levels in these cells [35-38]. Thus far, few studies have been performed to determine a physiological or pathological expression of TG2 in monocytes/macrophages in vivo. One of which is in a mouse model of atherosclerosis, showing increased TG2 immunoreactivity in infiltrated macrophages in the lesions, limiting lesion size [39].

As inflammation can alter TG2 expression, we characterized the inflammatory status of MS patient-derived monocytes and revealed that these cells expressed significantly lower mRNA levels of IL-1 $\beta$. Interestingly, expression levels of either TNF- $\alpha$ or anti-inflammatory IL-1ra and TGF- $\beta 1$ were unaffected. 

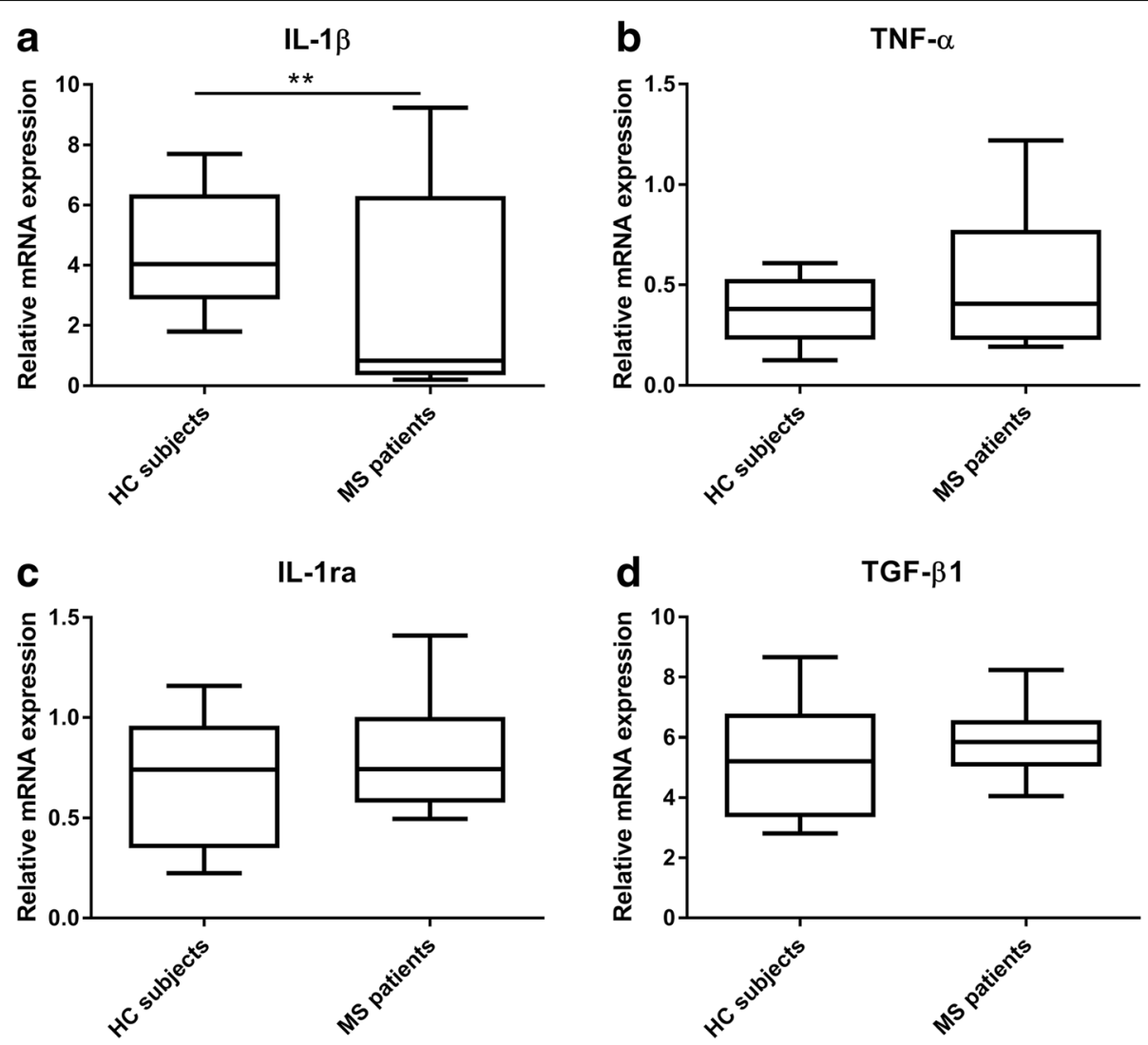

Fig. $2 \mathrm{IL}-1 \beta, T N F-\alpha, I L-1 \mathrm{ra}$, and TGF- $\beta 1$ mRNA levels in MS patient/HC subject-derived monocytes. $\mathrm{QPCR}$ analysis was performed to detect a IL-1 $\beta$ ( $\mathrm{HC} N=9 / \mathrm{MS} N=15), \mathbf{b}$ TNF-a (HC N=10/MS $N=13), \mathbf{c} \| \mathrm{L}-1 \mathrm{ra}(\mathrm{HC} N=8 / \mathrm{MS} N=14)$, and $\mathbf{d}$ TGF- $\beta 1$ (HC $N=8 / \mathrm{MS} N=14)$ mRNA levels in primary monocytes from MS patients and HC subjects. Data are shown in box-and-whiskers plots in which the median is represented by a horizontal line within the box, and the lower and upper whiskers represent the 5 and 95 percentiles. ${ }^{* *} p<0.01$. MS multiple sclerosis, HC healthy controls
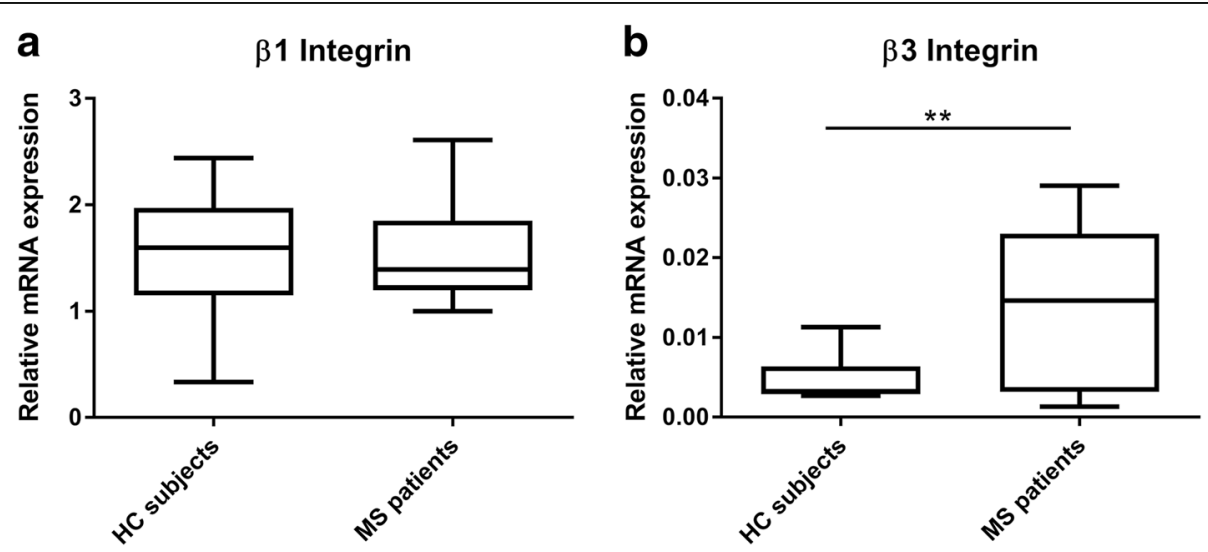

Fig. $3 \beta 1$ and $\beta 3$ integrin mRNA levels in MS patient/HC subject-derived monocytes. qPCR analysis was performed to detect a $\beta 1$ integrin ( $H C N=8 / M S N=14)$ and $\mathbf{b} \beta 3$ integrin ( $H C N=7 / M S N=15)$ mRNA levels in primary monocytes from MS patients and $H C$ subjects. Data are shown in box-and-whiskers plots in which the median is represented by a horizontal line within the box, and the lower and upper whiskers represent the 5 and 95 percentiles. ${ }^{* *} p<0.01$. MS multiple sclerosis, HC healthy controls 

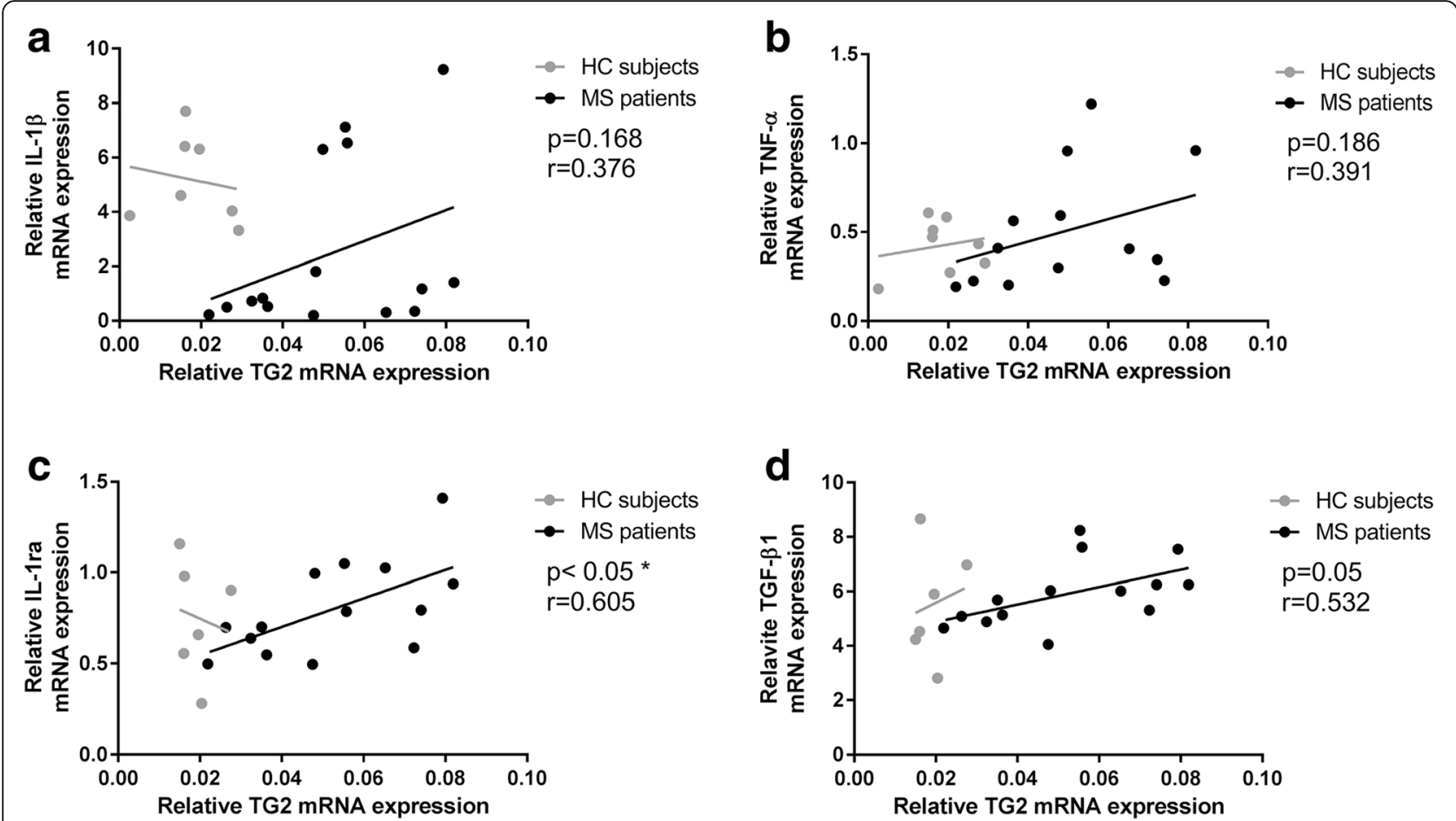

Fig. 4 Correlation of TG2 mRNA levels with pro/anti-inflammatory mediators. Pearson correlation analysis was performed to correlate TG2 mRNA levels with a IL-1 $\beta$, b TNF- $a, \mathbf{c} I L-1$ ra, and $\mathbf{d}$ TGF- $\beta 1$ mRNA levels in MS patient-derived monocytes (black line) and HC subject-derived monocytes (gray line). ${ }^{*} p<0.05$. MS multiple sclerosis, HC healthy controls

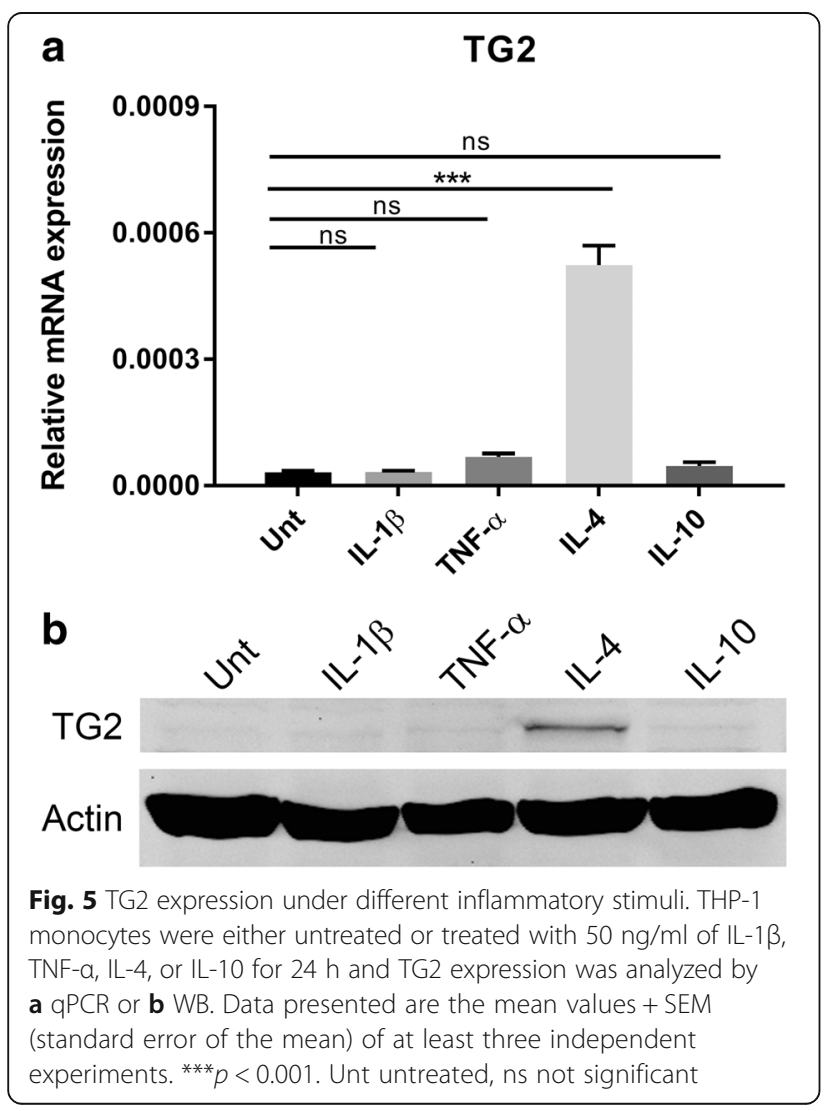

Although, we cannot exclude the presence of separate cell populations with each specific pro- or antiinflammatory phenotype, our data suggest that MS patient-derived monocytes have a mixed inflammatory phenotype, which is in agreement with the intermediate activation status displayed by monocyte-derived macrophages in active demyelinating MS lesions [40].

Noteworthy, elevated $\beta 3$ integrin mRNA levels in MS patients indicate an increase migratory capacity of the cells $[41,42]$. On the contrary, mRNA expression levels of the adhesion molecule $\beta 1$ integrin were not affected.

In addition, our observation that TG2 does not correlate either with IL-1 $\beta$ or TNF- $\alpha$ expression but correlated positively with the expression of two anti-inflammatory markers, i.e., IL-1ra and TGF- $\beta 1$ in MS monocytes, suggests that MS patient-derived monocytes expressing higher levels of TG2 have a more anti-inflammatory profile. We thus questioned what factor(s) could enhance monocyte-derived TG2, whose expression is known to be modulated by several inflammatory stimuli $[27,43,44]$, due to the presence of various inflammatory factor-related response elements in the promotor region [45]. As inflammation occurs during MS pathogenesis, we determined the effect of inflammatory mediators on TG2 expression. In THP-1 cell, known to be responsive to inflammatory stimuli [46, 47], predominantly IL-4 induced TG2 mRNA and protein 

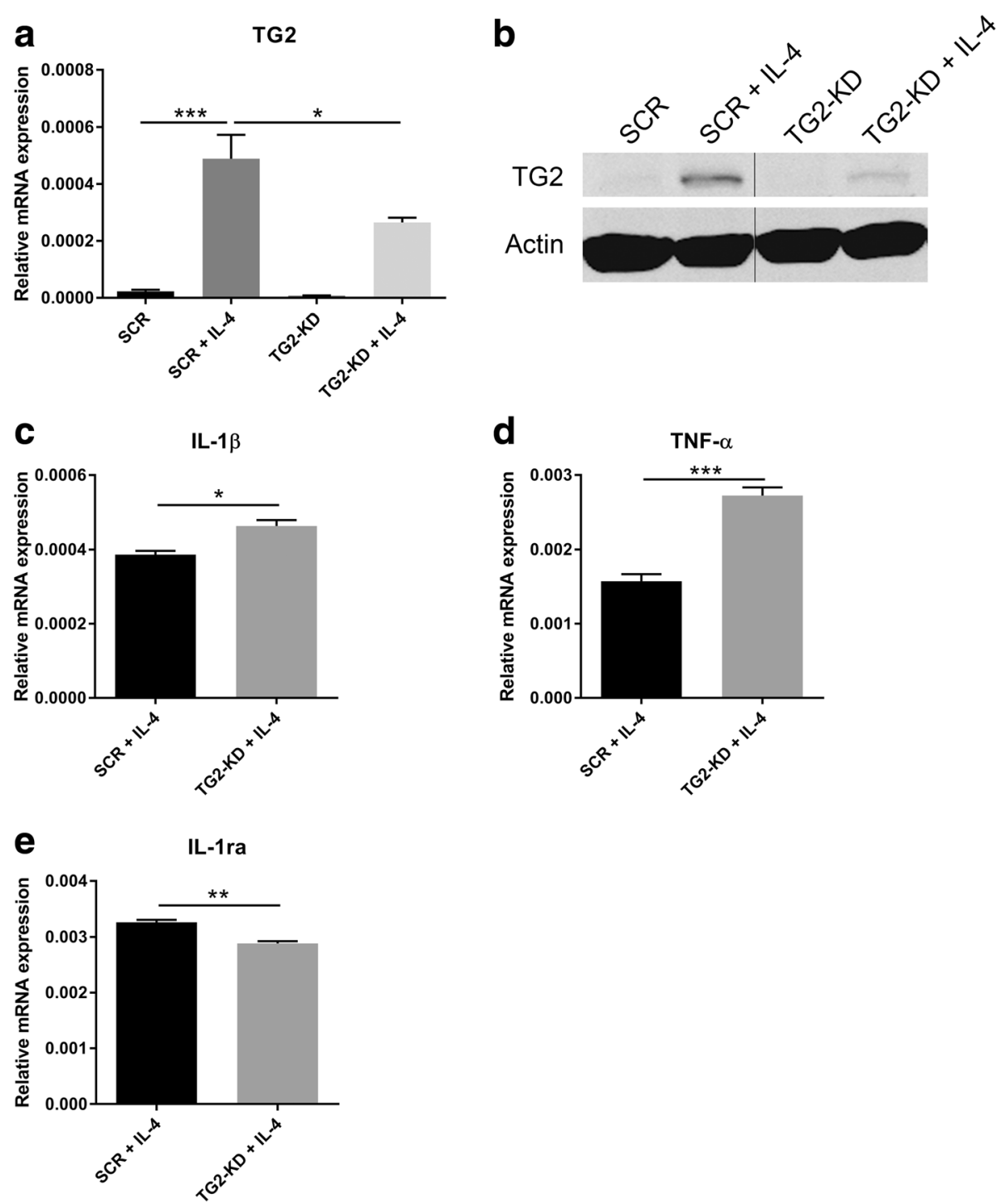

Fig. 6 Knockdown of TG2 expression drives IL-4-activated THP-1 monocytes into a pro-inflammatory phenotype. Lentiviral particles were used to efficiently knockdown TG2 expression in THP-1 monocytes as confirmed both by a qPCR or $\mathbf{b}$ WB. To study the phenotype of TG2-KD cells, mRNA expression levels of $\mathbf{c} I L-1 \beta$, $\mathbf{d}$ TNF- $a$, and $\mathbf{e}$ IL-1 ra were measured by qPCR in SCR or TG2-KD THP-1 monocytes activated for $24 \mathrm{~h}$ with IL-4 $(50 \mathrm{ng} / \mathrm{ml})$. Data presented are the mean values + SEM (standard error of the mean) of at least three independent experiments. ${ }^{*} p<0.05$, ${ }^{* *} p<0.01,{ }^{* * *} p<0.001$. SCR scramble control, TG2-KD TG2 knockdown

upregulation. These data suggest that the increased TG2 mRNA expression levels observed in MS patientderived monocytes could, directly or indirectly, be mediated by circulating or autocrine IL-4, whose presence was described to be enhanced both in serum and in mononuclear cells of MS patients compared to HC subjects [48-51]. Subsequently, we found that knockdown of TG2 resulted in a pro-inflammatory phenotype of IL-4-treated THP-1 monocytes as indicated by the increased mRNA levels of IL- $1 \beta$ and TNF- $\alpha$ and by the reduced mRNA levels of the anti-inflammatory cytokine IL-1ra. These data suggest that the presence of TG2 drives an anti-inflammatory phenotype of monocytes. In agreement with this observation, TG2 was recently established as an anti-inflammatory marker of IL-4-treated human and mouse macrophages [52].

Furthermore, it is known that IL- 4 affects adhesive/migratory properties of several cell types [53, 54]. Our findings regarding the attenuated adhesion, cytoskeleton rearrangement, and MMP-2 expression of IL-4-treated TG2-KD monocytes are the first to point out that these IL-4-mediated processes in human monocytes are, at least partly, regulated through TG2. 
a
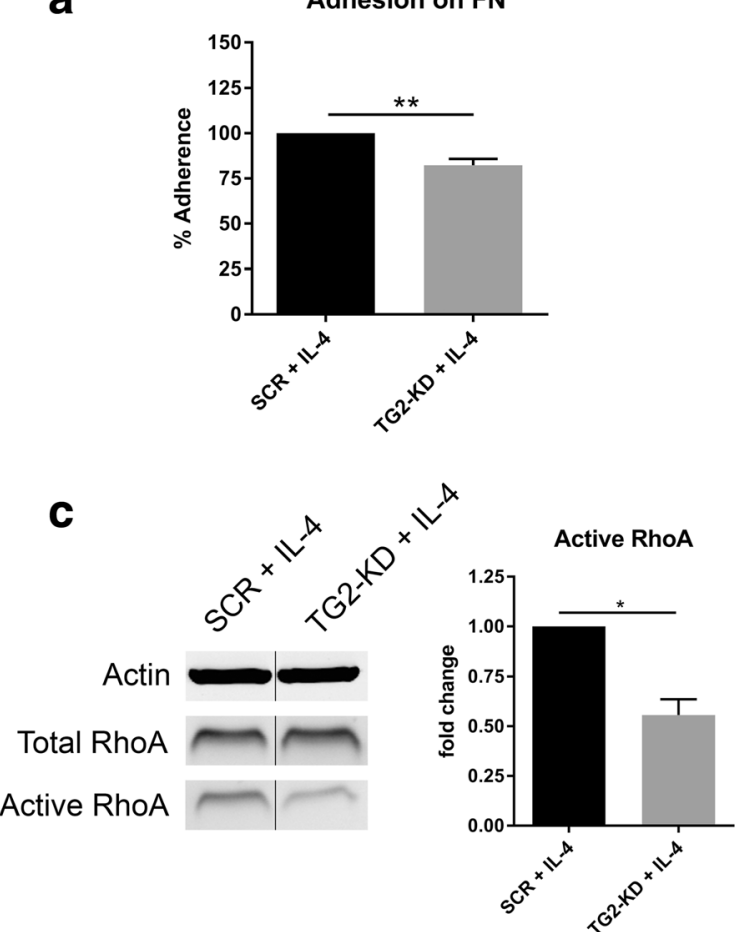

b

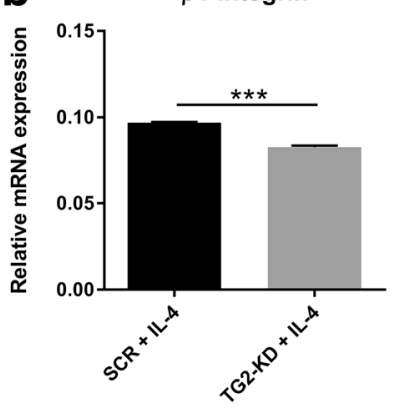

d

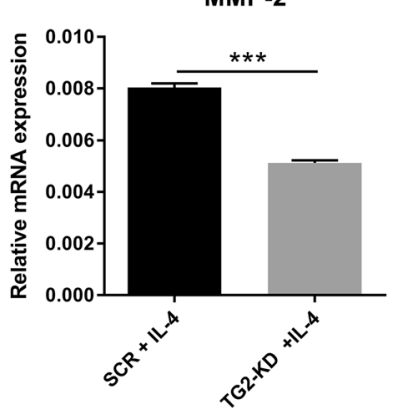

Fig. 7 Effect of TG2 knockdown on the adhesion/migration and cytoskeleton rearrangement in IL-4-activated THP-1 monocytes. SCR or TG2-KD monocytes were treated with $\mathrm{IL}-4(50 \mathrm{ng} / \mathrm{ml})$ for $24 \mathrm{~h}$ and then examined for a their ability to adhere onto a FN layer for $1 \mathrm{~h}, \mathbf{b}$ mRNA expression of $\beta 1$ integrin, $\mathbf{c}$ activation of the small GTPase protein RhoA, and $\mathbf{d}$ mRNA expression of MMP-2. Data presented are the mean values + SEM (standard error of the mean) of at least three independent experiments. ${ }^{*} p<0.05,{ }^{* *} p<0.01,{ }^{* * *} p<0.001$. SCR scramble control, TG2-KD TG2 knockdown

\section{Conclusion}

In this study, we established that TG2 mRNA levels are increased in monocytes derived from MS patients and correlates with anti-inflammatory cytokine expression, proposing a more anti-inflammatory status of the TG2expressing monocytes in MS. Furthermore, IL-4 is an important regulator of TG2 expression in THP1 monocytes and TG2 mediates IL-4-induced anti-inflammatory status of these cells as well as adhesion and cytoskeletal rearrangement in vitro. We thus propose that IL-4 upregulates TG2 expression in monocytes of MS patients, driving them into an anti-inflammatory status. This leads to the speculation that TG2 can mediate the enhanced adhesion of anti-inflammatory-tuned monocytes to the CNS endothelium of MS patients.

\section{Additional file}

Additional file 1: TG2 expression in untreated and drug-treated MS patients. qPCR analysis was performed to detect TG2 in primary human monocytes isolated from untreated $(N=10)$ and drug-treated $(N=5) \mathrm{MS}$ patients. Data are shown in box-and-whisker plots in which the median is represented by the horizontal line within the box, and the lower and upper whiskers represent the 5 and 95 percentiles. (TIFF 1769 kb)

\section{Abbreviations}

ANOVA: One-way analysis of variance; BBB: Blood-brain barrier;

BCA: Bicinchoninic acid; CNS: Central nervous system; DMT: Diseasemodifying therapies; DTT: Dithiothreitol; EAE: Experimental autoimmune encephalomyelitis; ECM: Extracellular matrix; FN: Fibronectin;

GAPDH: Glyceraldehyde-3-phosphate-dehydrogenase; HC: Healthy control; IL: Interleukin; IL-1ra: IL-1 receptor antagonist; MMP: Matrix metalloproteinase; MS: Multiple sclerosis; NGF: Nerve growth factor; PBMC: Peripheral blood mononuclear cells; PBS: Phosphate-buffered saline;

PMSF: Phenylmethylsulfonyl fluoride; POLR2F: Polymerase II polypeptide F; PP-MS: Primary progressive; qPCR: Semi-quantitative real-time PCR; RRMS: Relapsing-remitting MS; RT: Room temperature; SCR: Scramble control; SD: Standard deviation; SDS: Sodium dodecyl sulfate; SEM: Standard error of the mean; shRNA: Short hairpin RNA; TG2: Tissue transglutaminase or transglutaminase 2; TG2-KD: TG2-knockdown; TGF: Transforming growth factor; TNF: Tumor necrosis factor; Unt: Untreated; WB: Western blotting

\section{Acknowledgements}

We thank all MS patients and HC subjects for giving their consent to contribute to this study.

\section{Funding}

This work was supported by European Union Framework Programme 7 Marie Curie TRANSPATH ITN (grant no. 289964) and by the Dutch MS Research Foundation (grant no. 14-865MS and no. 10-701MS).

\section{Availability of data and materials}

The datasets used and/or analyzed during the current study are available from the corresponding author on reasonable request. 


\section{Authors' contributions}

CS conceived and carried out experiments, analyzed the data, and wrote the paper; JB, MvE, and JvR helped in data collection; JK, CT, MM, BD, and PvdE helped in the data interpretation and provided critical feedback on the paper; AvD designed the study, conceived the experiments, and helped in the data interpretation and in the writing of the paper. All authors read and approved the submitted manuscript.

\section{Ethics approval and consent to participate}

The study was approved by the Medical Research Ethics Committees of the VU University Medical Center (VUmc) and Leiden University Medical Center (LUMC). All participants gave informed consent.

\section{Consent for publication}

Not applicable

\section{Competing interests}

The authors declare that they have no competing interests.

\section{Publisher's Note}

Springer Nature remains neutral with regard to jurisdictional claims in published maps and institutional affiliations.

\begin{abstract}
Author details
'Department of Anatomy and Neurosciences, Amsterdam Neuroscience, VU University Medical Center, Postbus 7057, 1007 MB Amsterdam, the Netherlands. ${ }^{2}$ Department of Immunohematology and Blood Transfusion, Leiden University Medical Center, Leiden, the Netherlands. ${ }^{3}$ Department of Neurology, VU University Medical Center, Amsterdam, the Netherlands. ${ }^{4}$ Department of Clinical Chemistry, VU University Medical Center, Amsterdam, the Netherlands. ${ }^{5}$ Department of Pathology, VU University Medical Center, Amsterdam, the Netherlands. ${ }^{6}$ Present Address: Brain Plasticity Group, Center for Neuroscience, Swammerdam Institute for Life Sciences, University of Amsterdam, Science Park 904, Amsterdam, the Netherlands.
\end{abstract}

Received: 10 October 2017 Accepted: 11 December 2017 Published online: 21 December 2017

\section{References}

1. Koch-Henriksen N, Sorensen PS. The changing demographic pattern of multiple sclerosis epidemiology. Lancet Neurol. 2010;9:520-32.

2. Noseworthy J, Lucchinetti C, Rodriguez M, Weinshenker B. Multiple sclerosis. N Engl J Med. 2000;343:938-52.

3. Lassmann $\mathrm{H}$, van Horssen J. The molecular basis of neurodegeneration in multiple sclerosis. FEBS Lett. 2011;585:3715-23.

4. Chigaev A, Zwartz G, Graves SW, Dwyer DC, Tsuji H, Foutz TD, et al. alpha4beta1 integrin affinity changes govern cell adhesion. J Biol Chem. 2003:278:38174-82.

5. Shamri R, Grabovsky V, Gauguet JM, Feigelson S, Manevich E, Kolanus W, et al. Lymphocyte arrest requires instantaneous induction of an extended LFA1 conformation mediated by endothelium-bound chemokines. Nat Immunol. 2005;6:497-506.

6. Adams CWM, Poston RN, Buk SJ. Pathology, histochemistry and immunocytochemistry of lesions in acute multiple sclerosis. J Neurol Sci. 1989:92:291-306.

7. Ajami B, Bennett JL, Krieger C, McNagny KM, Rossi FM. Infiltrating monocytes trigger EAE progression, but do not contribute to the resident microglia pool. Nat Neurosci. 2011;14:1142-9.

8. Brück W, Porada P, Poser S, Rieckmann P, Hanefeld F, Kretzschmarch HA, et al. Monocyte/macrophage differentiation in early multiple sclerosis lesions. Ann Neurol. 1995;38:788-96.

9. Hauser SL, Bhan AK, Gilles F, Kemp M, Kerr C, Weiner HL. Immunohistochemical analysis of the cellular infiltrate in multiple sclerosis lesions. Ann Neurol. 1986;19:578-87.

10. Huitinga I, Van Rooijen N, De Groot CJ, Uitdehaag BM, Dijkstra CD. Suppression of experimental allergic encephalomyelitis in Lewis rats after elimination of macrophages. J Exp Med. 1990;172:1025-33.

11. Tran EH, Hoekstra K, van Rooijen N, Dijkstra CD, Owens T. Immune invasion of the central nervous system parenchyma and experimental allergic encephalomyelitis, but not leukocyte extravasation from blood, are prevented in macrophage-depleted mice. J Immunol. 1998;161:3767-75.
12. McQualter JL, Bernard CC. Multiple sclerosis: a battle between destruction and repair. J Neurochem. 2007;100:295-306.

13. Miller E. Multiple Sclerosis. In: Ahmad S, editor. Neurodegenerative diseases. US: Springer; 2012. p. 222-38.

14. Boven LA, Van Meurs M, Van Zwam M, Wierenga-Wolf A, Hintzen RQ, Boot $R G$, et al. Myelin-laden macrophages are anti-inflammatory, consistent with foam cells in multiple sclerosis. Brain. 2006;129:517-26.

15. Elkabes S, DiCicco-Bloom EM, Black IB. Brain microglia/macrophages express neurotrophins that selectively regulate microglial proliferation and function. J Neurosci. 1996;16:2508-21.

16. Mosser DM, Edwards JP. Exploring the full spectrum of macrophage activation. Nat Rev Immunol. 2008;8:958-69.

17. Denney L, Kok WL, Cole SL, Sanderson S, McMichael AJ, Ho LP. Activation of invariant NKT cells in early phase of experimental autoimmune encephalomyelitis results in differentiation of Ly6Chi inflammatory monocyte to M2 macrophages and improved outcome. J Immunol. 2012;189:551-7.

18. Mikita J, Dubourdieu-Cassagno N, Deloire MS, Vekris A, Biran M, Raffard G, et al. Altered M1/M2 activation patterns of monocytes in severe relapsing experimental rat model of multiple sclerosis. Amelioration of clinical status by M2 activated monocyte administration. Mult Scler. 2011;17:2-15.

19. Vaknin I, Kunis G, Miller O, Butovsky O, Bukshpan S, Beers DR, et al. Excess circulating alternatively activated myeloid (M2) cells accelerate ALS progression while inhibiting experimental autoimmune encephalomyelitis. PLoS One. 2011;6:e26921.

20. Bayardo M, Punzi F, Bondar C, Chopita N, Chirdo F. Transglutaminase 2 expression is enhanced synergistically by interferon-gamma and tumour necrosis factor-alpha in human small intestine. Clin Exp Immunol. 2012;168:95-104.

21. Kim SY, Jeong EJ, Steinert PM. IFN-gamma induces transglutaminase 2 expression in rat small intestinal cells. J Interf Cytok Res. 2002;22:677-82.

22. Shin DM, Jeon JH, Kim CW, Cho SY, Lee HJ, Jang GY, et al. TGF-beta mediates activation of transglutaminase 2 in response to oxidative stress that leads to protein aggregation. FASEB J. 2008;22:2498-507.

23. Yanagawa Y, Hiraide S, Matsumoto M, Shimamura K, Togashi H. Enhanced transglutaminase 2 expression in response to stress-related catecholamines in macrophages. Immunobiology. 2014;219:680-6.

24. van Strien ME, de Vries HE, Chrobok NL, Bol JG, Breve JJ, van der Pol SM, et al. Tissue transglutaminase contributes to experimental multiple sclerosis pathogenesis and clinical outcome by promoting macrophage migration. Brain Behav Immun. 2015;50:141-54.

25. Akimov SS, Belkin AM. Cell surface tissue transglutaminase is involved in adhesion and migration of monocytic cells on fibronectin. Blood. 2001;98:1567-76.

26. Polman CH, Reingold SC, Banwell B, Clanet M, Cohen JA, Filippi M, et al. Diagnostic criteria for multiple sclerosis: 2010 revisions to the McDonald criteria. Ann Neurol. 2011;69:292-302.

27. van Strien ME, Breve JJ, Fratantoni S, Schreurs MW, Bol JG, Jongenelen CA, et al. Astrocyte-derived tissue transglutaminase interacts with fibronectin: a role in astrocyte adhesion and migration? PLoS One. 2011;6:e25037.

28. Ruijter JM, Ramakers C, Hoogaars WM, Karlen Y, Bakker O, Van den Hoff MJB, et al. Amplification efficiency: linking baseline and bias in the analysis of quantitative PCR data. Nucleic Acids Res. 2009;36:e45.

29. Chanput W, Mes J, Vreeburg RA, Savelkoul HF, Wichers HJ. Transcription profiles of LPS-stimulated THP-1 monocytes and macrophages: a tool to study inflammation modulating effects of food-derived compounds. Food Funct. 2010;1:254-61.

30. Graesser D, Mahooti S, Haas T, Davis S, Clark RB, Madri JA. The interrelationship of alpha4 integrin and matrix metalloproteinase-2 in the pathogenesis of experimental autoimmune encephalomyelitis. Lab Investig. 1998;78:1445-58.

31. Yang $L$, Zheng Z, Zhou Q, Bai X, Fan $L$, Yang $C$, et al. miR-155 promotes cutaneous wound healing through enhanced keratinocytes migration by MMP-2. J Mol Histol. 2017;48:147-55.

32. Wilhelmus MM, de Jager M, Bakker EN, Drukarch B. Tissue transglutaminase in Alzheimer's disease: involvement in pathogenesis and its potential as a therapeutic target. J Alzheimers Dis. 2014;42(Suppl 3):S289-303.

33. Rauhavirta T, Hietikko M, Salmi T, Lindfors K. Transglutaminase 2 and transglutaminase 2 autoantibodies in celiac disease: a review. Clin Rev Allergy Immunol. 2016; doi:10.1007/s12016-016-8557-4.

34. Agnihotri N, Mehta K. Transglutaminase-2: evolution from pedestrian protein to a promising therapeutic target. Amino Acids. 2017:49:425-39. 
35. Curro M, Ferlazzo N, Risitano R, Condello S, Vecchio M, Caccamo D, et al. Transglutaminase 2 and phospholipase A(2) interactions in the inflammatory response in human Thp-1 monocytes. Amino Acids. 2014;46:759-66.

36. Frisdal E, Lesnik P, Olivier M, Robillard P, Chapman MJ, Huby T, et al. Interleukin-6 protects human macrophages from cellular cholesterol accumulation and attenuates the proinflammatory response. J Biol Chem. 2011;286:30926-36.

37. Hodrea J, Demeny MA, Majai G, Sarang Z, Korponay-Szabo IR, Fesus L. Transglutaminase 2 is expressed and active on the surface of human monocyte-derived dendritic cells and macrophages. Immunol Lett. 2010;130:74-81.

38. Murtaugh MP, Arend WP, Davies PJ. Induction of tissue transglutaminase in human peripheral blood monocytes. J Exp Med. 1984;159:114-25.

39. Boisvert WA, Rose DM, Boullier A, Quehenberger O, Sydlaske A, Johnson KA, et al. Leukocyte transglutaminase 2 expression limits atherosclerotic lesion size. Arterioscler Thromb Vasc Biol. 2006;26:563-9.

40. Vogel DY, Vereyken EJ, Glim JE, Heijnen PD, Moeton M, van der Valk P, et al. Macrophages in inflammatory multiple sclerosis lesions have an intermediate activation status. J Neuroinflamm. 2013;10:35.

41. Brilha S, Wysoczanski R, Whittington AM, Friedland JS, Porter JC. Monocyte adhesion, migration, and extracellular matrix breakdown is regulated by integrin alphaVbeta3 in mycobacterium tuberculosis infection. J Immunol. 2017;199:982-91.

42. Leavesley DI, Schwartz MA, Rosenfeld M, Cheresh DA. Integrin beta1-and beta3-mediated endothelial cell migration is triggered through distinct signaling mechanisms. J Cell Biol. 1993:121:163-70.

43. Kawabe K, Takano K, Moriyama M, Nakamura Y. LipopolysaccharideStimulated Transglutaminase 2 Expression Enhances Endocytosis Activity in the Mouse Microglial Cell Line BV-2. Neuroimmunomodulation. 2015;22:2439.

44. Johnson K, Hashimoto S, Lotz M, Pritzker K, Terkeltaub R. Interleukin-1 induces pro-mineralizing activity of cartilage tissue transglutaminase and factor XIlla. Am J Pathol. 2001:159:149-63.

45. Gundemir S, Colak G, Tucholski J, Johnson GV. Transglutaminase 2: a molecular Swiss army knife. Biochim Biophys Acta. 2012;1823:406-19.

46. Krakauer T, Oppenheim JJ. IL-1 and tumor necrosis factor-alpha each upregulate both the expression of IFN-gamma receptors and enhance IFNgamma-induced HLA-DR expression on human monocytes and a human monocytic cell line (THP-1). J Immunol. 1993;150:1205-11.

47. Murthy PK, Dennis VA, Lasater BL, Philipp MT. Interleukin-10 modulates proinflammatory cytokines in the human monocytic cell line THP-1 stimulated with Borrelia burgdorferi lipoproteins. Infect Immunol. 2000;68:6663-9.

48. Hohnoki K, Inoue A, Koh CS. Elevated serum levels of IFN-gamma, IL-4 and TNF-alpha/unelevated serum levels of IL-10 in patients with demyelinating diseases during the acute stage. J Neuroimmunol. 1998;87:27-32.

49. Kallaur AP, Oliveira SR, Colado Simao AN, Delicato de Almeida ER, Kaminam Morimoto H, Lopes J, et al. Cytokine profile in relapsingremitting multiple sclerosis patients and the association between progression and activity of the disease. Mol Med Rep. 2013;7:1010-20.

50. CZ L, Jensen MA, Arnason BG. Interferon gamma- and interleukin-4-secreting cells in multiple sclerosis. J Neuroimmunol. 1993;46:123-8.

51. Soderstrom M, Hillert J, Link J, Navikas V, Fredrikson S, Link H. Expression of IFN-gamma, IL-4, and TGF-beta in multiple sclerosis in relation to HLA-DW2 phenotype and stage of disease. Mult Scler. 1995;1:173-80.

52. Martinez FO, Helming L, Milde R, Varin A, Melgert BN, Draijer C, et al. Genetic programs expressed in resting and IL-4 alternatively activated mouse and human macrophages: similarities and differences. Blood. 2013;121:e57-69.

53. Chiba Y, Todoroki M, Misawa M. Interleukin-4 upregulates RhoA protein via an activation of STAT6 in cultured human bronchial smooth muscle cells. Pharmacol Res. 2010;61:188-92.

54. Elenstrom-Magnusson C, Chen W, Clinchy B, Obrink B, Severison E. IL-4induced $B$ cell migration involves transient interactions between beta 1 integrins and extracellular matrix components. Int Immunol. 1995;7:567-73.

\section{Submit your next manuscript to BioMed Central and we will help you at every step:}

- We accept pre-submission inquiries

- Our selector tool helps you to find the most relevant journal

- We provide round the clock customer support

- Convenient online submission

- Thorough peer review

- Inclusion in PubMed and all major indexing services

- Maximum visibility for your research

Submit your manuscript at www.biomedcentral.com/submit
() BioMed Central 